\title{
Polyurethane grouting materials with different compositions for the treatment of mud pumping in ballastless track subgrade beds: properties and application effect
}

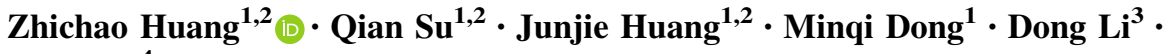 \\ Ting Liu ${ }^{4}$
}

Received: 7 June 2021/Revised: 24 December 2021/ Accepted: 29 December 2021/Published online: 15 February 2022

(C) The Author(s) 2022

\begin{abstract}
Mud pumping in subgrade beds under ballastless tracks will deteriorate the dynamic performance of infrastructure under railway lines, reduce the smoothness of the railway lines, and seriously affect the comfort and safety of the trains. Due to their good mechanical properties, twocomponent polyurethane materials can be used for grouting to treat the fouling problems caused by ballastless track mud pumping. To develop a polyurethane formula suitable for the treatment of ballastless track mud pumping, we first performed indoor experiments to investigate the mechanical properties and gelation time of polyurethane elastomers synthesized with different raw material composition ratios, to determine an optimal composition ratio of the raw materials. Then, we conducted a dynamic field test to verify the remediation effect of the polyurethane material fabricated according to the design ratio. The results showed that polyurethane grouting material with the selected design ratios improved the contact characteristics between the surface layer of the subgrade bed and the base plate in the area, coordinating the dynamic response
\end{abstract}

Junjie Huang

junjiehuang@swjtu.edu.cn

Zhichao Huang

hzc2018@my.swjtu.edu.cn

1 School of Civil Engineering, Southwest Jiaotong University, Chengdu 610031, China

2 Key Laboratory of High-Speed Railway Engineering of Ministry of Education, Southwest Jiaotong University, Chengdu 610031, China

3 China Railway Fourth Survey and Design Institute Group Co., Ltd., Wuhan 430000, China

4 China Railway Construction Kunlun Investment Group Co., Ltd., Chengdu 610040, China between the track structure and the subgrade bed. Thus, the obtained polyurethane grouting material could be used to renovate mud pumping areas of ballastless tracks with a good treatment effect.

Keywords Ballastless track - Mud pumping - Twocomponent polyurethane $\cdot$ Proportioning design $\cdot$ Field dynamic test

\section{Introduction}

By the end of 2020, the total operating mileage of highspeed railways in China reached $39,000 \mathrm{~km}$, with ballastless tracks being the main track structure type due to their excellent integrity, superior durability, and good strength properties. High-speed railways are subjected to fast traveling speeds and intensive operating conditions. Under the coupling effect of long-term dynamic loading from trains and natural forces, the materials used for expansion joints in the base plates (support layer) and the side joints between the base plates and the subgrade closure layer have experienced performance degradation [1]. These materials have gradually cracked, forming water seepage channels, and water from the track surface has penetrated into the surfaces of the subgrade bed along this channel. Repeated impacts due to traffic loading have also generated excess pore water pressure along the contact interface between the surface layer of the subgrade bed and the base plate. Under the action of excess pore water pressure [2], fine particles in the surface layer of the subgrade bed will flow out of the track surface along the seepage channel, as 
shown in Fig. 1a, resulting in mud pumping in the subgrade bed grouting, deteriorating the dynamic performance of subgrade structure [3], reducing the smoothness of the railway line [4], and seriously affecting the comfort and safety of the trains. Figure $1 \mathrm{~b}$ shows the mud pumping of a ballastless track subgrade during operation.

Due to the differences between ballastless track structures, traditional rectification measures for the foundation beds of ballasted tracks are not applicable to ballastless tracks. Chemical grouting [5] has engineering advantages such as convenient operation, less construction disturbance, a short construction time, and high curing strength [6]. It has been widely used in highway engineering, water conservation dam engineering, building structure reinforcements, underground engineering, and other fields [7-12]. It was then introduced into the field of railway engineering [13-15]. Polyurethane elastomers are mainly synthesized from raw materials such as polyisocyanates, oligomer polyols, and chain extenders, in which the polyisocyanate reacts with the chain extenders, forming the hard segments, while the oligomer polyols form the soft segments, and the soft and hard segments are alternatively arranged in the chain $[16,17]$. Considering the superior mechanical properties of polyurethane elastomers, polyurethane grouting is one of the main effective engineering methods for treating mud pumping of ballastless tracks. Although some studies have found that harmful gases can be produced during the preparation and synthesis of polyurethane [18, 19], we noted that many types of components are used for polyurethane synthesis, and these components are not equally harmful. The polyurethane used to treat the mud pumping of ballastless track subgrade beds mainly includes isocyanate, soft polyether polyol, hard polyether polyol, 1,4butanediol, and xylene. Among them, methylene polyphenyl polyisocyanate (PAPI), which is non-toxic and harmless, is often used as isocyanate. Many studies (e.g., [20]) have shown that polyurethane elastomers have better corrosion, water, and fatigue resistance than polyurethane foams. In addition, polyurethane elastomers have excellent flame-retardant performance, and are even capable of selfextinguishing after ignition.

Polyurethane grouting is widely applied in highways, housing construction, and underground engineering. Polyurethane grouting materials have been investigated experimentally and/or theoretically from many aspects, including material synthesis and modification [21-23], mechanical and macroscopic properties [24-28], the evolution mechanism of macro-mechanical properties and microstructure characteristics [29-32], and the diffusion mechanism and expansion characteristics of polymer grout [33-37]. However, existing studies have mainly focused on the engineering backgrounds of water conservation, structure lifting, and foundation treatment and reinforcement. These applications are considerably different from the treatment of ballastless track mud pumping. Furthermore, in these studies, the components of the polymer materials and the studied variables were relatively simple, and the effects of different material components on the mechanical properties of polyurethane elastomers were not considered.

In this work, we conducted laboratory tests to study the evolution of compressive, tensile, and bonding strengths of polyurethane elastomers under the effects of different material components. On this basis, the optimal ratio of a polyurethane elastomer suitable for the treatment of mud pumping in subgrade beds under ballastless tracks was put forward. In addition, we performed in situ dynamic tests to verify the efficacy of the proposed polyurethane elastomer grouting treatment.

\section{Proportion design of polyurethane grouting materials}

Remediation work is generally arranged during twilight operations, that is, from 12:00 am to 4:00 am (a total of $4 \mathrm{~h}$ ), to ensure the normal operations of the existing highspeed railway lines. Therefore, the special grouting medium environment and operating time limit pose significant
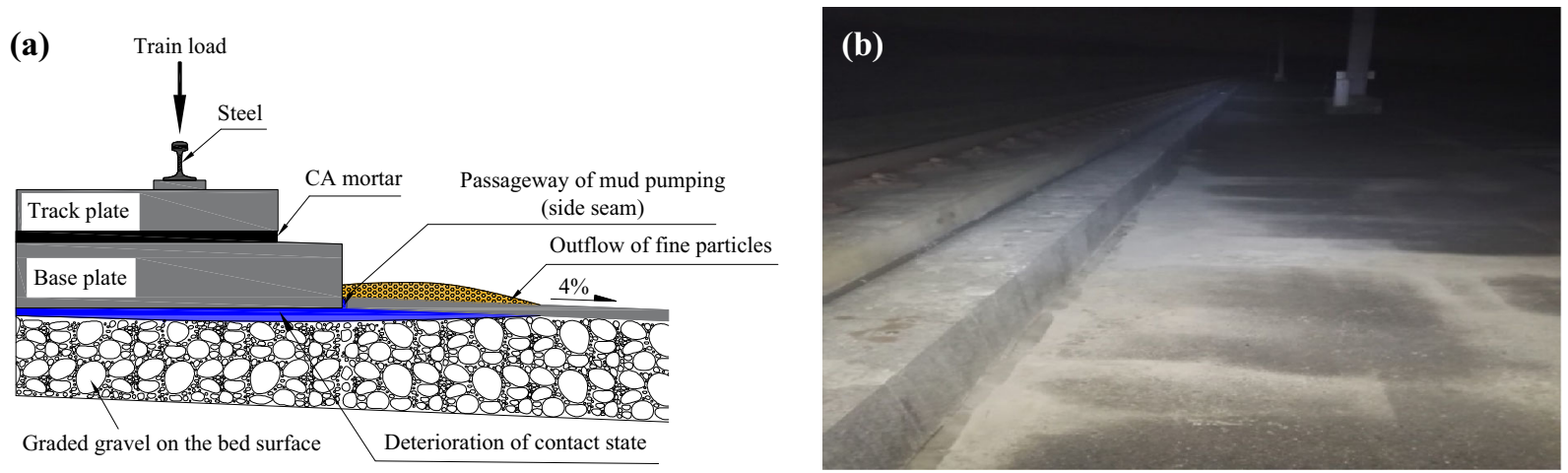

Fig. 1 Mud pumping: a mechanism of mud pumping; $\mathbf{b}$ mud pumping of a ballastless track during operation 
challenges for material performance. For example, the material should have a suitable viscosity, good injectability, and the ability to flow through fine cracks. Also, the material should also have good early strength, a short curing time, and the ability to form a high-strength elastomer. Lastly, the material should exhibit good bonding performance and be able to bond firmly with the surface layer of the subgrade bed and the base plate (supporting layer), forming a sandwich layered structure. Currently, theoretical research on polymer grouting for the fouling treatment of ballastless track foundation beds lags behind engineering applications. Furthermore, there have been no systematic reports on material performance parameter index requirements and test methods, and normative documentation is lacking.

The mechanical properties of polyurethane elastomers are mainly provided by the isocyanates and polyols. Polyols constitute the soft segments of the polyurethane molecular chain, providing good toughness and ensuring that the polyurethane elastomer exhibits good elastic deformation properties. Isocyanate reacts with alcohol to form strongly polar and rigid urethane groups, which form the hard segments of the polyurethane chain, endowing the elastomer with compressive and tensile strength. The active hydrogen molecules in the chain-extending cross-linking agent react with the isocyanate groups, producing a crosslinking chemical reaction. This reaction affects the polyurethane elastomer structure system, causing the polyurethane to form a chain or networked structure, which improves the distribution of the soft and hard segments in the polyurethane elastomer, as well as the mechanical properties and damage resistance of the polyurethane elastomer [38, 39]. Solvents, which can promote chemical reactions between the components, are the main additives in polyurethane synthesis, while chain-extending crosslinking agents and solvents are the main components that affect the viscosity and gel time of the polyurethane slurry.

Considering the above analysis, the design of the polyurethane ratio must consider the effects of multiple components; however, each component will have a different degree of influence on the mechanical properties of the elastomer. Therefore, the single-factor test method was adopted in this study. In this method, the contents of polyol and isocyanate were set as the preferred factors, while the quantities of the other components were left unchanged. First, the optimal ratio between polyols and isocyanate content was determined by analyzing the test results. By using chain-extending cross-linking agent and solvent content as variables, the determined design ratio was tested, and an optimal ratio of polyurethane grouting material suitable for ballastless track mud pumping treatment was proposed.

\subsection{Raw material selection and polyurethane synthesis}

\subsubsection{Raw materials}

In this study, the polyurethane grouting material was mainly composed of isocyanate, hard polyether polyols, soft polyether polyols, a chain extension cross-linking agent, and a solvent. There are many types of isocyanates, and toluene diisocyanate (TDI), diphenylmethane diisocyanate (MDI) and polymethylene polyphenyl isocyanate (PAPI) are the most commonly used for polyurethane production. Among these, PAPI has high functionality and a low acid value. As a result, the reaction and curing speeds will be faster when polyurethane is processed with PAPI. The molecular structure of PAPI contains multiple benzene rings, endowing the PAPI-fabricated polyurethane material with higher strength. Thus, PM200 PAPI was selected in this study, and the basic physical performance indices are shown in Table 1. Hard polyether polyol has a low molecular weight and dense branched chains, giving the polyurethane high hardness and deformation resistance properties, while soft polyether polyol can increase the elasticity of the polyurethane, enhance the elongation at break, and improve its resistance to plastic deformation.

Table 1 Physical properties of PM200

\begin{tabular}{lllll}
\hline Mass fraction of $\mathrm{NCO}(\%)$ & Density $\left(\mathrm{g} / \mathrm{cm}^{3}\right)$ & Viscosity $(\mathrm{mPa} \cdot \mathrm{s})$ & Acidity $(\%)$ & Average functionality \\
\hline $30.5-32.0$ & $1.22-1.25$ & $150-250$ & $\leq 0.03$ & $2.6-2.7$ \\
\hline
\end{tabular}

The density and viscosity are measured at $25{ }^{\circ} \mathrm{C}$

Table 2 Basic physical properties of polyether polyols

\begin{tabular}{lllllll}
\hline Type of polyol & Material $(\mathrm{mg} \mathrm{KOH} / \mathrm{g})$ & Moisture & $\begin{array}{l}\text { Viscosity }\left(25^{\circ} \mathrm{C}\right) \\
(\mathrm{mPa} \cdot \mathrm{s})\end{array}$ & $\mathrm{pH}$ & $\mathrm{K}^{+}$concentration (mg/kg) & Functionality \\
\hline Soft polyether polyol & $25-29$ & $\leq 0.05 \%$ & $\leq 7000$ & $6-9$ & $\mathrm{NA}$ & 2 \\
Hard polyether polyol & $112 \pm 3.5$ & $\leq 0.05 \%$ & $100-200$ & $5-7$ & $\leq 3$ & 2 \\
\hline
\end{tabular}


Table 3 The purity of main materials for synthetic polyurethane

\begin{tabular}{lll}
\hline Serial no. & Material & Product standards \\
\hline 1 & PM200 & Industrially pure \\
2 & Soft polyether polyol & Industrially pure \\
3 & Hard polyether polyol & Industrially pure \\
4 & 1,4-butanediol & Industrially pure \\
5 & Xylene & Analytically pure \\
\hline
\end{tabular}

The basic physical performance indices of the two types of polyether polyols are shown in Table 2 . The main role of a chain extender cross-linker is to extend the molecular chain, increase the relative molecular weight of polyurethane, and improve the functionality of the polyurethane polymer, giving the cured product better strength, heat resistance, and creep resistance. Chain extenders can be divided into alcohols and amines, and among these, ethylene glycol and 1,4-butanediol are the most commonly used chain extenders. Thus, 1,4-butanediol was selected in this study. The main functions of a solvent are to reduce viscosity and improve the injectability of the slurry, and many types of solvents are used in polyurethane synthesis. The solvent selection should be determined according to factors such as the similarity of the solubility parameters (SP) between the polyurethane molecules and the solvent, polarity similarity, and the volatilization rate of the solvent itself. In this study, we used xylene as the solvent. The purities of the main materials used for polyurethane synthesis are shown in Table 3, where the analytical purity was $99.7 \%$, and industrial purity was about $90 \%$.

\subsubsection{Polyurethane formulation}

The preparation process for the polyurethane samples fabricated in this study is shown in Fig. 2. First, the soft polyether polyol and hard polyether polyol were stirred evenly at specific proportions to form a mixed alcohol solution. Then, an appropriate amount of PM200, 1,4-butanediol, and xylene were evenly mixed, and the slurry was gelled to form the polyurethane elastomer. The test was also produced according to the preliminary test experience of the research groups in [40, 41].

\subsection{Experimental methods}

\subsubsection{Compression performance test}

In this work, the selected sample size was $20 \mathrm{~mm} \times 20$ $\mathrm{mm} \times 20 \mathrm{~mm}$, according to the standard Epoxy resin grouting material for concrete cracks (JC/T1041-2007) [42]. The polyurethane grouting material was prepared as described in Sect. 2.1.2, and then poured into $20 \mathrm{~mm} \times$ $20 \mathrm{~mm} \times 20 \mathrm{~mm}$ cubic test molds, placed in a temperature control box for $24-48 \mathrm{~h}$, and then demolded. The ambient temperature in the temperature control box was set to $23{ }^{\circ} \mathrm{C}$, and the relative humidity was $50 \%$. The prepared samples are shown in Fig. 3a. Three samples were made for each sample group, and the average of the test results was used as the basis for analysis.

As shown in Fig. 3b, in this study, we used a universal testing machine for compression testing, according to the Resin casting body performance test method (JB/T 25672008) [43], where the controlled loading rate was $5 \mathrm{~mm} /$ min. Then, the pressure load was gradually applied until the sample broke, and the selected peak point in the sample stress-strain curve was used as the ultimate value to measure the compressive strength of the sample. To measure the elastic modulus, the hierarchical loading rate was controlled at $2 \mathrm{~mm} / \mathrm{min}$, and the maximum load was $50 \%$ of the failure load of the sample. The elastic modulus of the sample was calculated according to Eq. (1):

$E_{\mathrm{c}}=\frac{H \times \Delta F}{B^{2} \times \Delta H}$,

where $E_{\mathrm{c}}$ is the modulus of elasticity $(\mathrm{MPa}), H$ is the original height of the sample $(\mathrm{mm}), \Delta F$ is the load increment $(\mathrm{N}), B$ is the sample width $(\mathrm{mm})$, and $\Delta H$ is the vertical deformation increment that corresponds to the load increment $\Delta F(\mathrm{~mm})$.

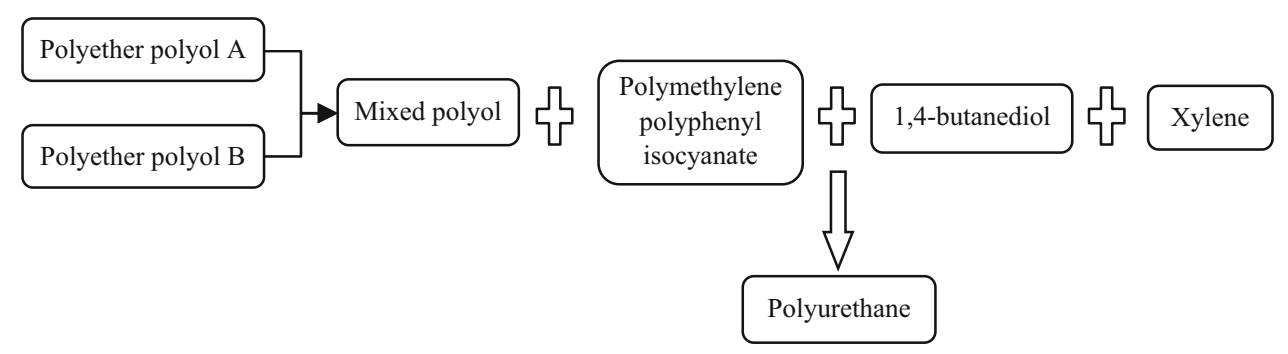

Fig. 2 The synthesis process of polyurethane 

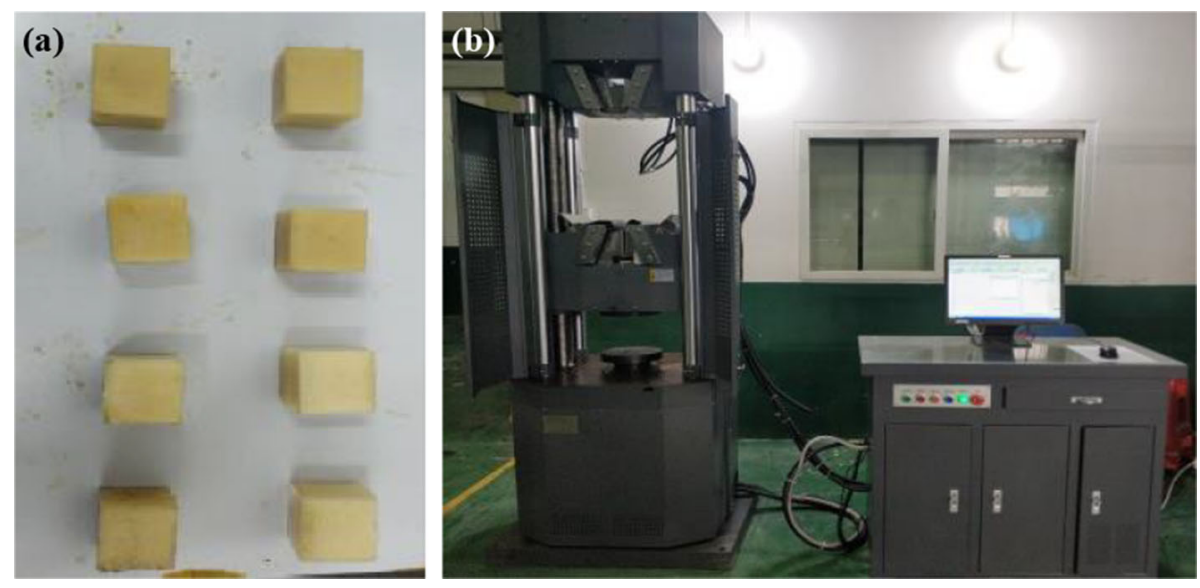

Fig. 3 Polyurethane compression test: a samples for compression test; $\mathbf{b}$ electronic universal testing machine

\subsubsection{Tensile performance test}

The tensile test was conducted according to JB/T 25672008 standard, and the sample preparation process and maintenance methods were the same as those stated in Sect. 2.2.1. The formed samples are shown in Fig. 4a. A universal testing machine was used to test the tensile properties of the polyurethane elastomers, as shown in Fig. 4b. During the installation of each sample, the center axis of the sample was aligned with the center lines of the upper and lower clamps of the universal testing machine, and the tensile loading rate was set to $10 \mathrm{~mm} / \mathrm{min}$. Tension was then applied to the sample at a uniform speed. When the sample broke, the test was stopped, and the peak point in the stress-strain curve from the tensile test was read as the ultimate tensile strength of the sample. Then, the elongation at break of the sample was calculated according to Eq. 2, and the average value of the samples was used as the basis for analysis. Equation 2 is given by

$\varepsilon_{\mathrm{t}}=\frac{\Delta L}{L}$,

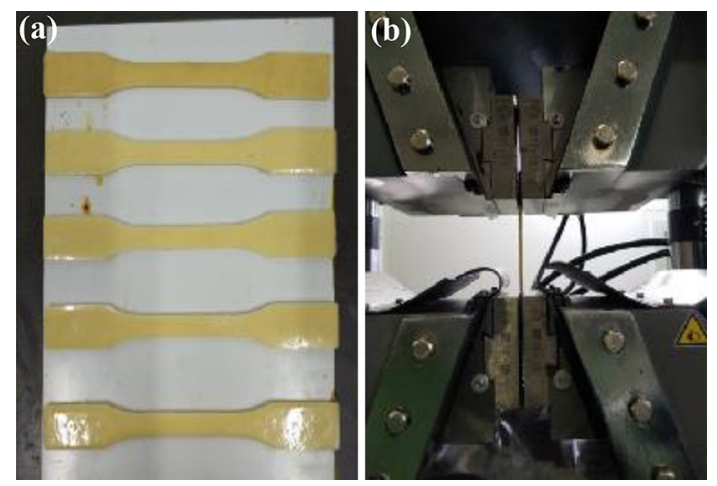

Fig. 4 Tensile test of the polyurethane elastomer: a samples for tensile test; $\mathbf{b}$ sample fixing where $\varepsilon_{\mathrm{t}}$ is the elongation at break of the sample (\%), $\Delta L$ is the elongation at break of the sample $(\mathrm{mm})$, and $L$ is the length of the sample (mm).

\subsubsection{Bonding performance test}

The bonding performance test was conducted according to the Epoxy grouting resin for concrete crack (JC/T 1041) and Technical specification of injection materials for repair of cracks in concrete (G/T 333) standards. First, two concrete test blocks $100 \times 100 \times 100 \mathrm{~mm}$ in size were prepared, and then a $15-\mathrm{mm}$-thick layer of polyurethane grouting material was poured between the two test blocks, forming a sandwich sample after curing, as shown in Fig. 5a. To test the effects of wet and dry environments on the bonding strength of the polyurethane grouting material, the cured concrete test block was soaked in water for one day, and then the polyurethane grouting material was poured between the test blocks to create the samples. (a)

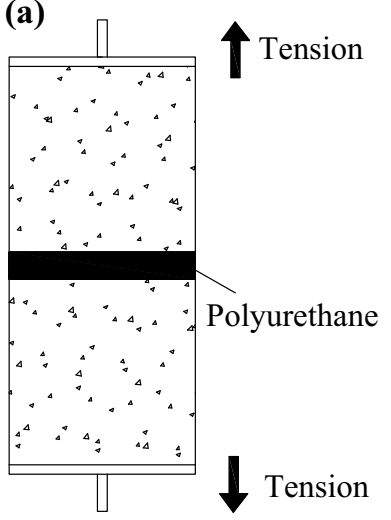

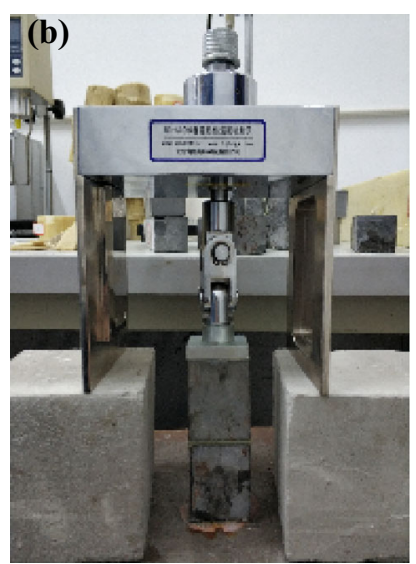

Fig. 5 Bonding performance test of the polyurethane elastomer: a samples for bonding test; $\mathbf{b}$ intelligent bonding strength tester 
An HC-6000C intelligent bonding strength tester was used to conduct the bonding strength tests, as shown in Fig. 5b, and the tensile loading rate was $100 \mathrm{~N} / \mathrm{s}$.

\subsubsection{Gel time and viscosity tests}

Grouting treatment to resolve ballastless track mud pumping is an operation that is performed during twilight hours. Thus, the limitations of the grouting medium environment and working time require that the polyurethane grouting material has good fluidity and a fast gel time. According to the standard Test method for unsaturated polyester resin (GB/T 7193-2008) [44], we used a viscometer to test the viscosity and gel times of the polyurethane grouting material, as shown in Fig. 6. When testing the gel time, in this work we started timing from the moment the AB polyethers were mixed, and stopped timing when the viscosity reached $50 \mathrm{~Pa} \cdot \mathrm{s}$. At this point, the recorded time was the polyurethane grouting gel time.

\subsection{Analysis of test results}

\subsubsection{Evolution of the mechanical properties} of the polyurethane elastomers with different polyol mixing ratios

Soft and hard polyether polyols were mixed to make the polyols, and to determine their optimal mass ratio, we used the single-factor test method. The mass ratios of soft and hard polyether polyols were set as variables, and the quantities of the other components were fixed to generate the polyurethane elastomer. In this experiment, four mass ratios were designed, i.e., 4:1, 3:1, 2:1, 1:1, and 1:2. Figures 7,8 , and 9 show the compression, tensile, and adhesion performance test results of the polyurethane elastomers with different polyol mixing ratios, respectively. Figures 7 and 8 show that the different polyol

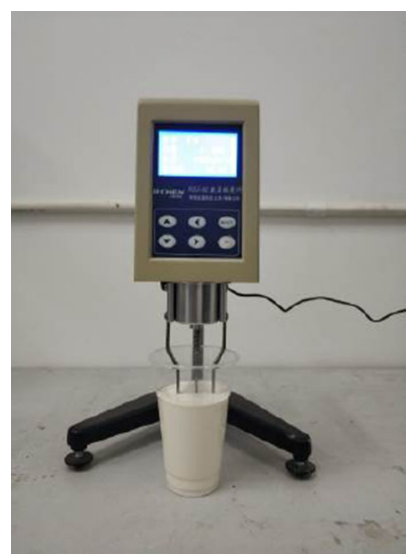

Fig. 6 Viscometer

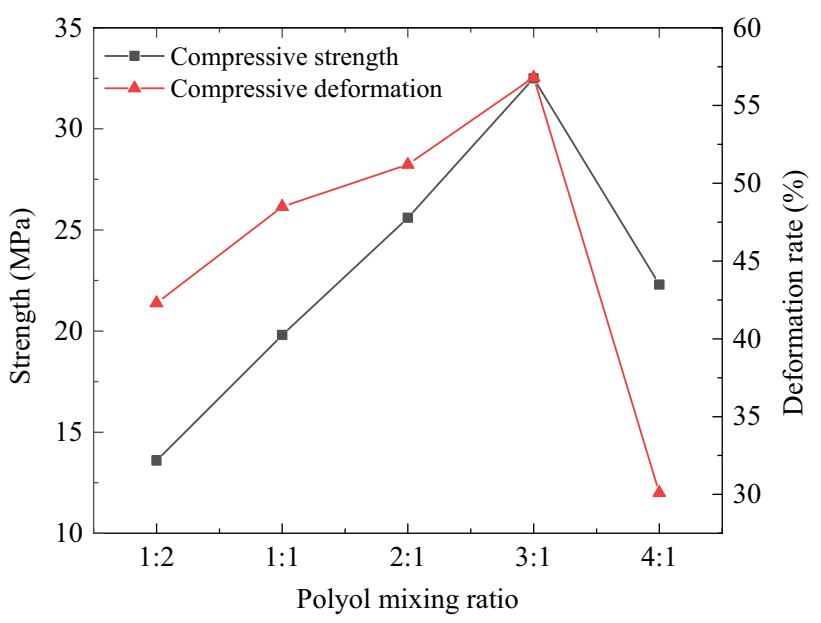

Fig. 7 Compressive strength and deformation of the polyurethane elastomers with different polyol mixing ratios (mixing ratio = quality of soft polyether polyols/quality of hard polyether polyols)

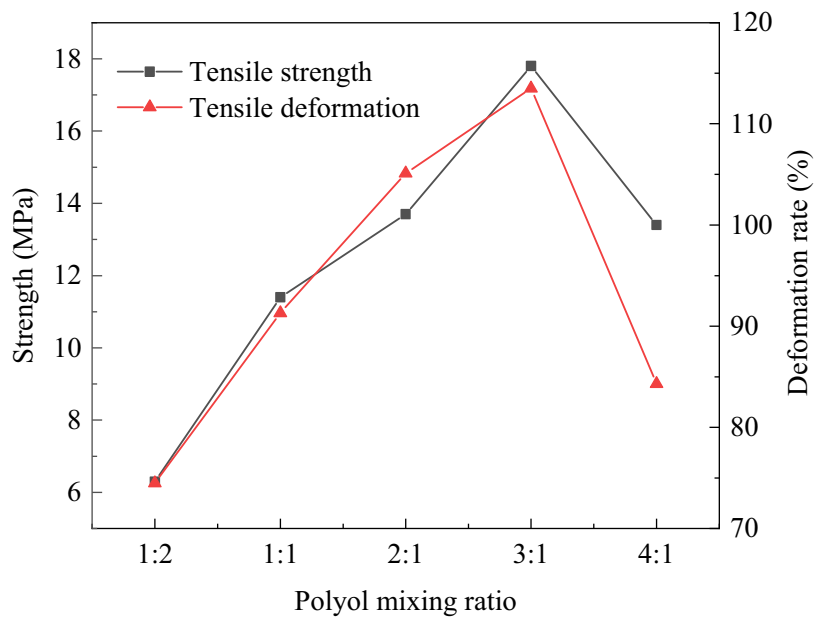

Fig. 8 Tensile strength and deformation of the polyurethane elastomers with different polyol mixing ratios

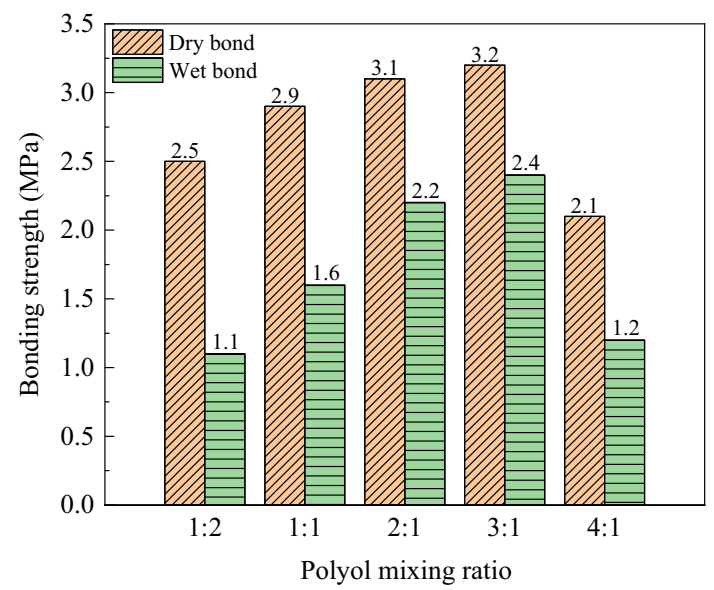

Fig. 9 Bonding strength results of the polyurethane elastomers with different polyol mixing ratios 
mixing ratios significantly influenced the strength and deformation properties of the polyurethane elastomers. When the polyol mixing ratio did not exceed $3: 1$, the compressive and tensile strengths of the polyurethane elastomer increased rapidly and approximately linearly as the amount of soft polyether polyol in the polyol increased. The corresponding compression and tensile deformation results also showed a linear growth trend. When the polyol mixing ratio exceeded $3: 1$, that is, when the soft polyether polyol content in the polyol exceeded $75 \%$, the strength of the polyurethane elastomer decreased rapidly, and the deformation rate decreased sharply. When the mass ratio of soft to hard polyether polyol was 1:2, the compressive strength of the polyurethane elastomer was 13.6 MPa, and the tensile strength was $6.3 \mathrm{MPa}$. When the mass ratio of soft to hard polyether polyol was 2:1, the compressive strength of the polyurethane elastomer was $25.6 \mathrm{MPa}$, and the tensile strength was $13.7 \mathrm{MPa}$. Thus, the soft polyether polyol had more of an effect on the mechanical properties of the polyurethane elastomer. When the polyol mixing ratio was 3:1, the strength and deformation values of the polyurethane elastomer reached their peak. At this point, the compressive strength was $30.2 \mathrm{MPa}$, the compressive deformation rate was $56.8 \%$, the tensile strength was 17.8 $\mathrm{MPa}$, and the tensile deformation rate was $113.5 \%$. Compared to the minimum strength performance parameters, the compressive strength increased by 2.4 times, and the compressive strength increased by 2.1 times.

The polyol in the test consisted of a blended system composed of soft and hard polyether polyols, which had typical particle dispersion characteristics [45]. The soft polyether polyol was a grafted polyether polyol that contained rigid vinyl monomers, copolymers, or self-polymers, such as styrene and acrylonitrile. This type of polyol gave the synthesized polyurethane elastomer a polyether matrix main chain. Its flexibility also ensured that the polyurethane elastomer had good tensile strength, compression resistance, and elastic deformation performance. Therefore, as the amount of soft polyether polyol increased, the mechanical properties of the polyurethane elastomers gradually improved; however, with an excessive amount of soft polyether polyols, the number of rigid polymer particles in the elastomer increased, the flexibility decreased, and the probability of brittle failure increased. This weakened the mechanical properties of the product.

Figure 9 depicts a histogram of the bonding strength results of the polyurethane elastomer with different polyol mixing ratios. In accordance with the aforementioned law, as the content of soft polyether polyol in the polyol increased, the bonding performance of the polyurethane elastomer gradually increased. When the ratio was $3: 1$, the material reached its peak value. At this point, the dry bonding strength of the polyurethane elastomer was
3.2 $\mathrm{MPa}$, and the wet bonding strength was $2.4 \mathrm{MPa}$. When the mixing ratio exceeded $3: 1$, the bonding performance of the polyurethane elastomer rapidly decreased. Thus, the bonding performance of the polyurethane elastomer was better in the dry environment than in the wet environment. This was because during synthesis of the polyurethane elastomer in the wet environment, isocyanate reacted with water, and some of the molecular bonds were broken, forming urea and amino radicals, and $\mathrm{CO}_{2}$ was released. However, the weak polarity of the amino and urea groups reduced the adhesive strength of polyurethane elastomer, and the produced $\mathrm{CO}_{2}$ was not completely discharged, which increased the cell diameter and its volume ratio in the elastomer; thus, reducing the adhesive strength of the polyurethane elastomer. The above analysis indicated that when the polyol mixing ratio was $3: 1$, the synthesized polyurethane elastomer exhibited superior mechanical properties.

\subsubsection{Effect of isocyanate content on the mechanical properties of the polyurethane elastomer}

Figures 10 and 11 show the compression and tensile performance test results of the polyurethane elastomer with different isocyanate contents. The figures show that the relationship curve between isocyanate content (PM200 content), strength, and deformation had a three-stage characteristic. (1) The first stage was characterized by increased strength and decreased deformation rate, where during the manufacturing of polyurethane elastomers, the isocyanates and polyols were mixed through chemical reactions, forming urethane groups with strong polarity and rigidity. This mixture constituted the hard segments in the molecular chain of the polyurethane elastomer. With an increase in PM200 content, the number of generated

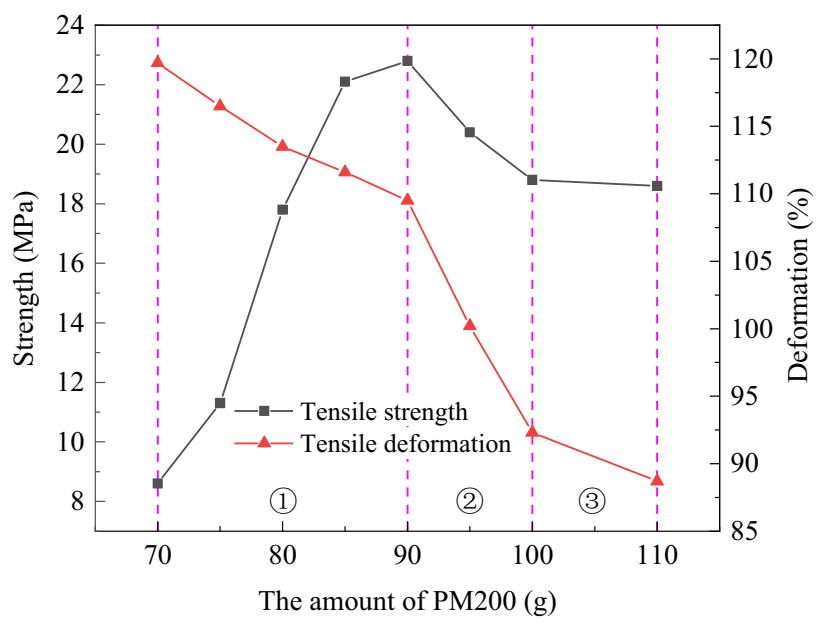

Fig. 10 Compressive strength and deformation of the polyurethane elastomers with different isocyanate contents 


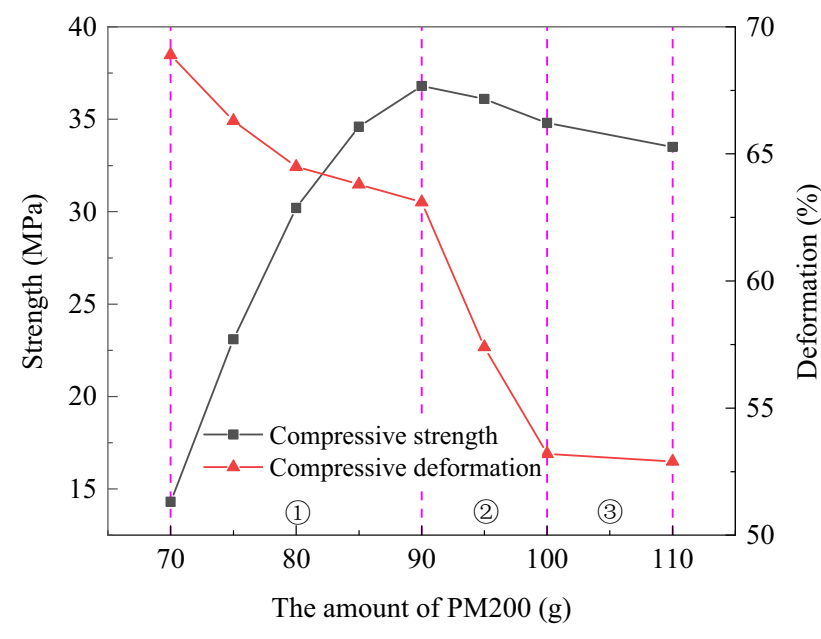

Fig. 11 Compressive strength and deformation of the polyurethane elastomers with different isocyanate contents

urethane groups increased rapidly, the amount of hard segments in the polyurethane elastomer molecular chain increased sharply, and the proportion of soft molecular segments chain decreased; thus, flexibility declined. Therefore, the strength of the polyurethane elastomer improved; however, the elastomer's resistance to deformation was reduced. When the content of PM200 was $90 \mathrm{~g}$, the strength of the polyurethane elastomer reached its maximum, with a compressive strength value of $36.8 \mathrm{MPa}$ and tensile strength value of $22.8 \mathrm{MPa}$. (2) In the second stage, the strength and deformation rates decreased synergistically. As the content of PM200 further increased and polyol content was limited, the chemical cross-linking reaction of isocyanates and polyols was not complete. As a result, a few isocyanates remained, and the molecular structures followed the remaining content changes gradually, which weakened the strength and deformation resistance abilities of the synthesized polyurethane elastomer. Deformation resistance declined faster than during the firststage attenuation rate. (3) The third stage consisted of performance retention. Rigid molecular chain content in the synthesized polyurethane elastomer became saturated, and the molecular structure was reconstructed. Therefore, the strength and deformation abilities of the polyurethane elastomer gradually stabilized.

Figure 12 shows a bonding strength bar graph of the polyurethane elastomers with different isocyanate (PM200) contents. As the content of PM200 increased, the bonding strength of the polyurethane elastomer and concrete gradually increased. When the content of PM200 was $90 \mathrm{~g}$, the polyurethane elastomer exhibited the best bonding strength, and the wet bonding strength reached $2.4 \mathrm{MPa}$, and the dry bonding strength reached $3.5 \mathrm{MPa}$. When the content of PM200 exceeded $90 \mathrm{~g}$, the bonding strength of the polyurethane elastomer decreased with increasing

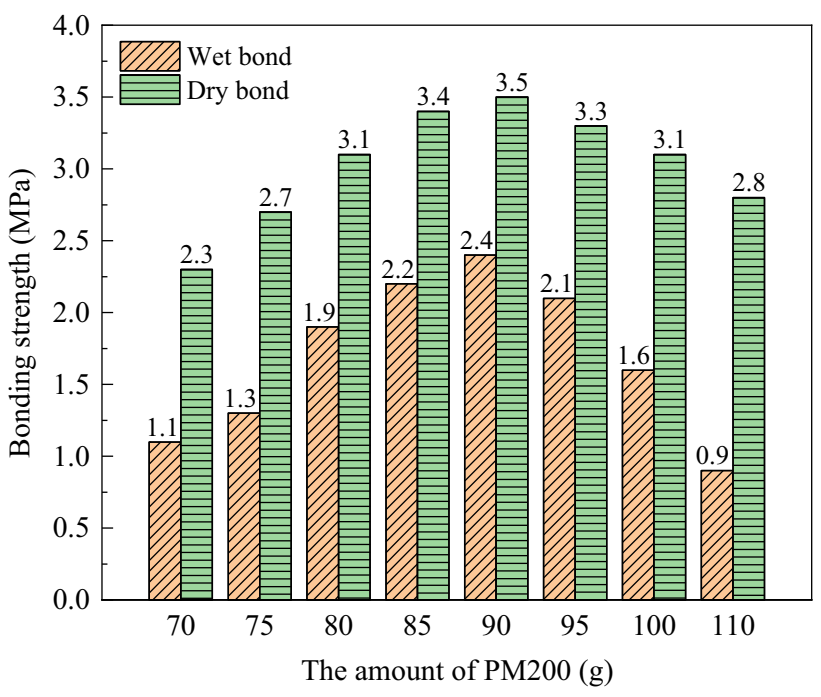

Fig. 12 Bonding strength of the polyurethane elastomers with different isocyanate contents

isocyanate content. The increase in PM200 content promoted molecular cross-linking and increased the proportion of polar groups in the molecular chain. Therefore, the bonding strength of the polyurethane elastomer improved. In the humid environment, the bonding strength of the polyurethane elastomers was evidently weaker than in the dry environment. This result was consistent with the analysis in the previous section. According to the test results in this section, isocyanate content had a greater impact on the mechanical properties of the polyurethane elastomer. In addition, an optimal value was found. Specifically, with $90 \mathrm{~g}$ of isocyanate, the synthesized polyurethane elastomer exhibited the best mechanical properties.

\subsubsection{Influence of chain-extending cross-linking agent content on the physical and mechanical properties of the polyurethane elastomer}

Figures 13 and 14 show the gel time and elastomer strength properties of the polyurethane grouting with different chain extender contents. These two figures indicated that the gel time and strength of the polyurethane slurry were affected by 1,4-butanediol content, and compared to the strength, 1,4-butanediol content had more of an effect on the gelation time of the polyurethane slurry. With increased 1,4butanediol content, the gel time of the polyurethane slurry decreased linearly, and the decrease was greater, while the $2 \mathrm{~h}$ compressive strength and $2 \mathrm{~h}$ tensile strength values of the polyurethane elastomer increased at a uniform rate. With $20 \mathrm{~g}$ of 1,4-butanediol content, the polyurethane slurry required $36 \mathrm{~min}$ to cure to form the elastomer, and its $2 \mathrm{~h}$ compressive strength and $2 \mathrm{~h}$ tensile strength values 
were 5.8 MPa and 3.4 MPa, respectively. With $35 \mathrm{~g}$ of 1,4butanediol, the gel time was shortened by $9 \mathrm{~min}$, and the curing time was $27 \mathrm{~min}$. Thus, the $2 \mathrm{~h}$ compressive strength of the elastomer increased by $217 \%$ to $12.6 \mathrm{MPa}$, and the $2 \mathrm{~h}$ tensile strength value increased by $276 \%$ to 9.4 MPa. The above phenomenon was attributed to the increase in glycol chain extender content, which accelerated the intermolecular cross-linking reaction rate, released more heat, shortened the curing time of the polyurethane, and increased the speed of strength formation. For the bonding strength of the polyurethane elastomer, the increase in 1,4-butanediol content promoted the crosslinking reaction rate, shortened the curing time, and enabled the material to quickly strengthen. With $27 \mathrm{~g}$ of 1,4-butanediol content, the dry bonding strength of the prepared elastomer was $3.7 \mathrm{MPa}$ and the wet bonding strength was $2.6 \mathrm{MPa}$. Thus, the bonding strength of the polyurethane elastomer decreased with increasing 1,4-butanediol content.

Figure 15 shows the influence of the chain extender (1,4-butanediol) content on the compressive/tensile strength (7 d) and deformation of the polyurethane elastomer. The glycol chain extender was flexible and with a small steric hindrance, which was beneficial for improving the degree of hydrogen bonding between the molecular chains, such as amino and urea groups [46]. With an increasing amount of 1,4-butanediol, the urea bonded amino groups and the ether groups in the soft segment became more active, and the number of generated hydrogen bonds increased. However, this increased the hardness of the molecular chain. By contrast, the specific gravity of the segments promoted the molecular interactions between the soft and hard segments. Therefore, as shown in Fig. 15, the strength and deformability of the polyurethane elastomer gradually increased for seven days with increasing

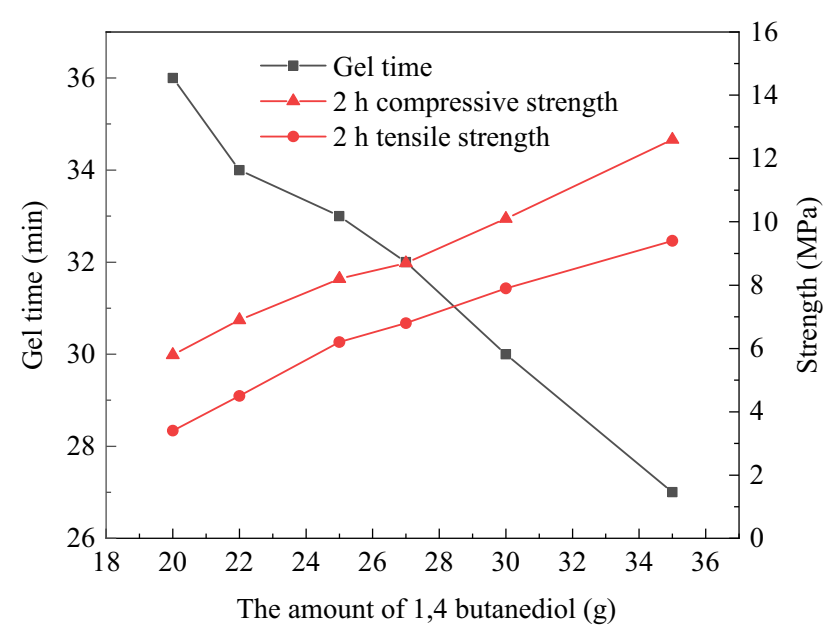

Fig. 13 Gel time and strength of the polyurethane elastomer with different cross-linking agent contents

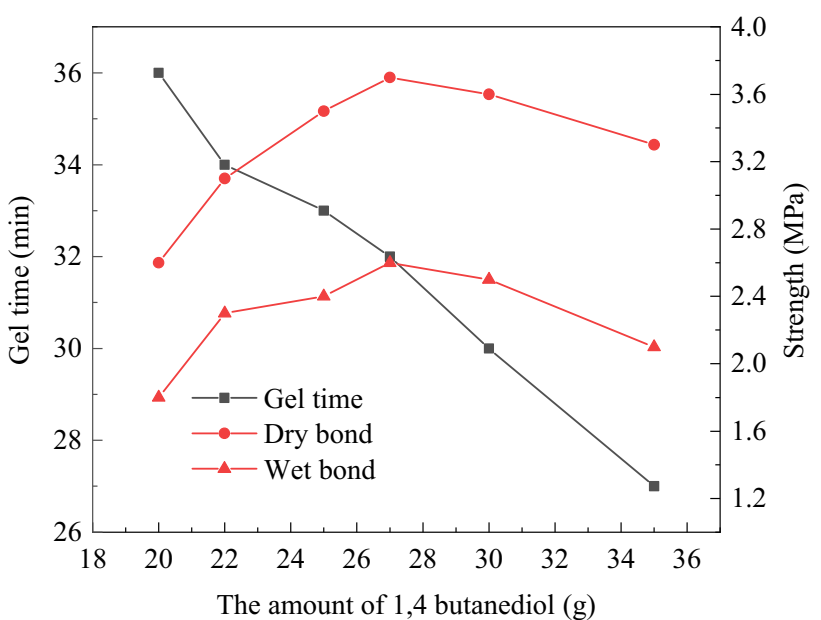

Fig. 14 Gel time and bonding strength of the polyurethane elastomer with different cross-linking agent contents

1,4-butanediol content. The hydrogen bonding effect was the best when 1,4-butanediol content was increased to $27 \mathrm{~g}$, and the 7-day strength and deformation ability properties of the prepared elastomer reached their maximum values. Thus, the compressive strength was 37.8 MPa, and the compressive deformation rate was $63.1 \%$. The tensile strength value was $24.1 \mathrm{MPa}$ and the tensile deformation rate was $98.3 \%$. When 1,4-butanediol content exceeded $27 \mathrm{~g}$, there was an excessive amount of hard segments, and the soft and hard segments in the molecular chain were unevenly distributed. This reduced the intermolecular cross-linking effect, which weakened the mechanical properties of the polyurethane elastomer. Therefore, the optimal content of 1,4-butanediol was $27 \mathrm{~g}$.

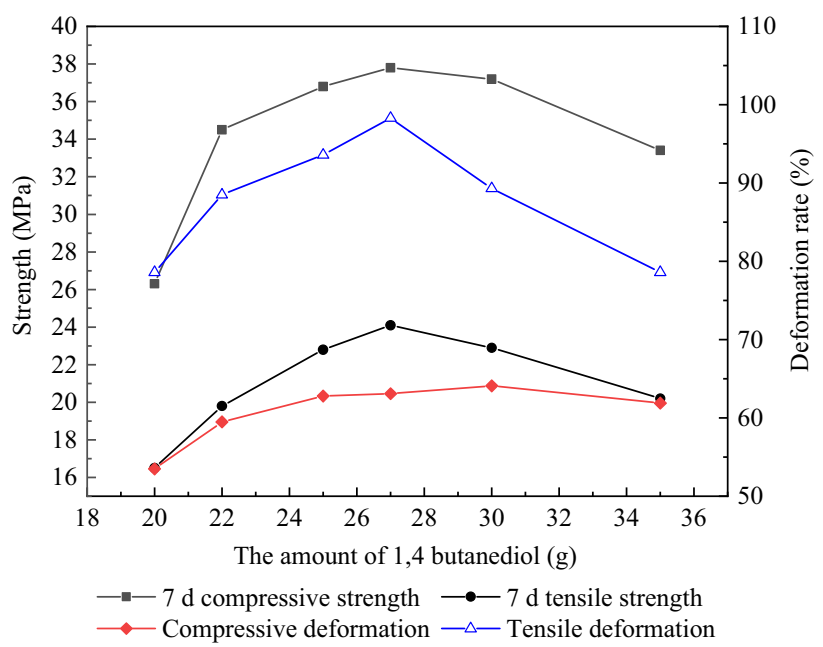

Fig. 15 Influence of chain extender (1,4-butanediol) content on the $7 \mathrm{~d}$ strengths and deformations of the polyurethane elastomer 


\subsubsection{Effect of solvent (xylene) content on the physical and mechanical properties of the polyurethane composite}

The effects of the different xylene contents on the gel time and viscosity of the polyurethane composite are shown in Fig. 16, showing that the gel time and viscosity were greatly affected by the xylene content. As the xylene content increased, the gel time of the polyurethane grouting material decreased rapidly. When the xylene content was $0 \mathrm{~g}$, the gel time of the polyurethane composite was $49 \mathrm{~min}$, and when the xylene content was $25 \mathrm{~g}$, the gel time was shortened to $30 \mathrm{~min}$, which was a decrease of about $39 \%$. Then, as the xylene content increased, the gel time of the polyurethane composite increased again. Therefore, the xylene solvent increased the gelation reaction rate of the polyurethane slurry so that it cured and formed in a shorter amount of time; however, when xylene content was too high, xylene solvation was excessive, which increased intermolecular fluidity. Thus, considering the gel time, the optimal amount of xylene was $25 \mathrm{~g}$, and at this point, the gel time of the polyurethane composite was $30 \mathrm{~min}$. Figure 16 shows that the viscosity of the polyurethane composite decreased with increasing xylene content, but the rates of decrease were different. When xylene content increased from 0 to $25 \mathrm{~g}$, the viscosity decreased from 1440 to $287 \mathrm{mPa} \cdot \mathrm{s}$; thus, the rate was evidently faster. When xylene content was greater than $25 \mathrm{~g}$, the change was smaller.

Figure 17 shows the changes in $2 \mathrm{~h}$ compressive and $2 \mathrm{~h}$ tensile strengths and gel time of the polyurethane elastomer with different xylene contents. Figure 18 shows the changes in bonding performance and gel time of the polyurethane elastomer with different xylene contents. From Fig. 17, when xylene content did not exceed $25 \mathrm{~g}$, although

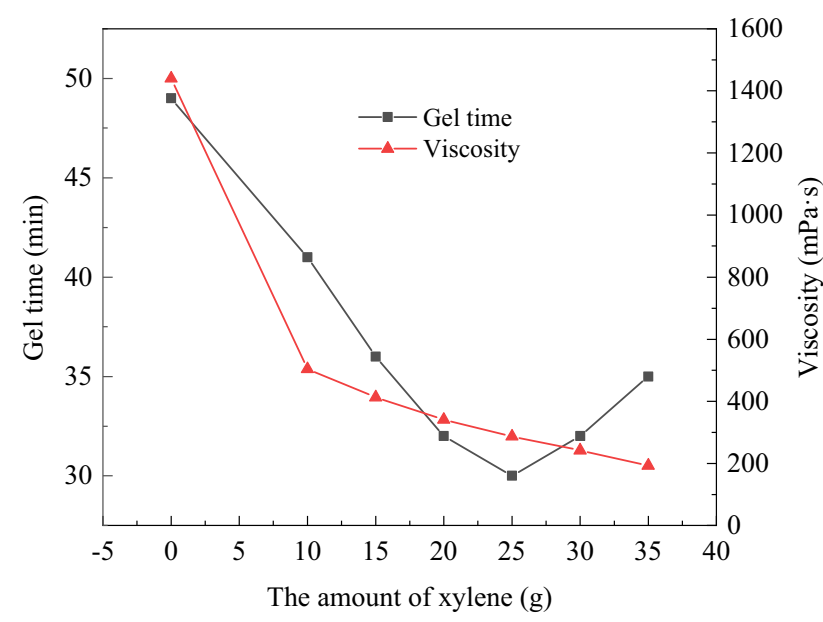

Fig. 16 Gel time and viscosity of the polyurethane composites with different xylene contents

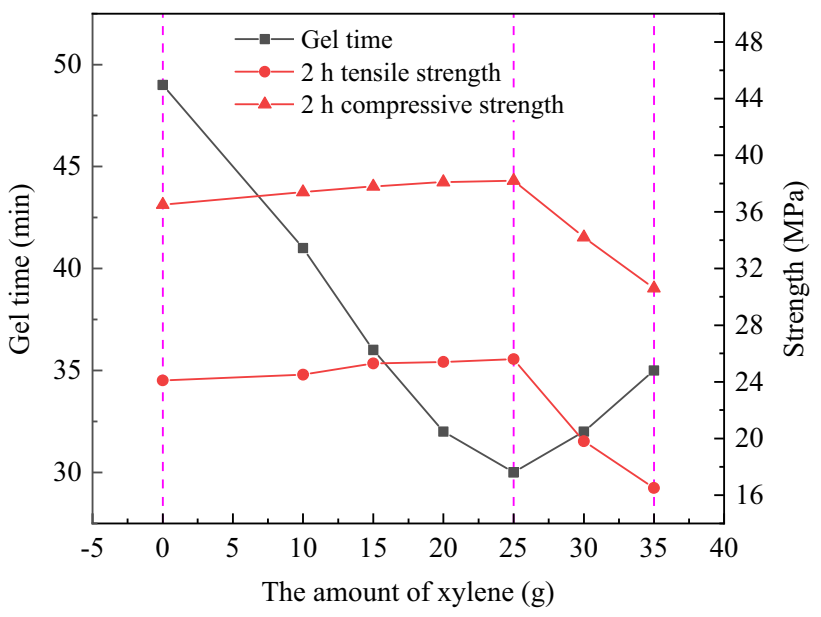

Fig. 17 Changes in compressive and tensile strengths and gel time of the polyurethane composite with different xylene contents

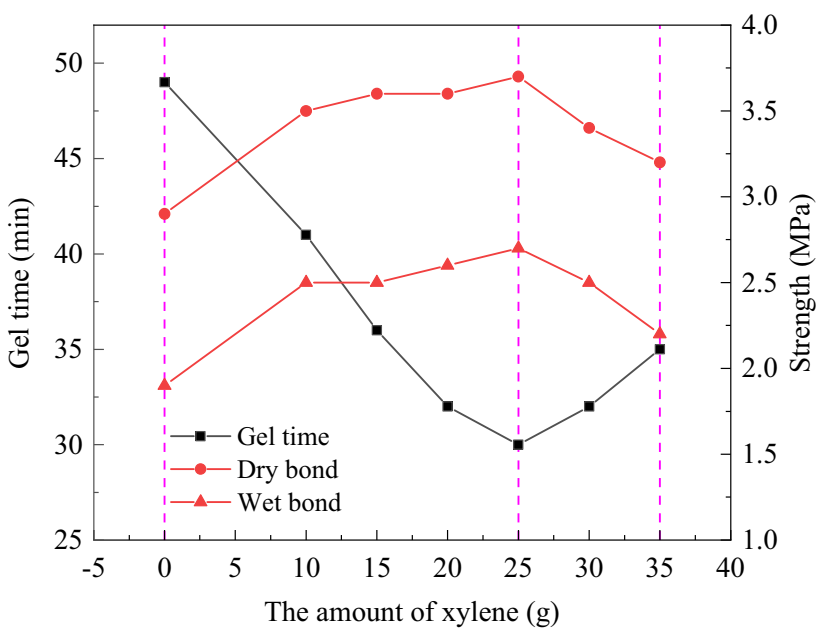

Fig. 18 Changes in bonding strength and gel time of the polyurethane composite with different xylene contents

the $2 \mathrm{~h}$ compressive and $2 \mathrm{~h}$ tensile strengths of the polyurethane elastomer improved, the differences were not large. When xylene content exceeded $25 \mathrm{~g}$, the $2 \mathrm{~h}$ compressive and $2 \mathrm{~h}$ tensile strengths of the polyurethane elastomer showed a relatively noticeable decline. Thus, appropriate xylene content improved the uniformity of the chemical reactions between the components and promoted the cross-linking between the soft and hard molecular chains, which improved the mechanical properties of the polyurethane elastomer. However, when xylene content was too high, excessive compounding reactions resulted in uneven distributions of the soft and hard molecular chains. This reduced the toughness of the polyurethane elastomer, increasing its brittleness, and decreasing its mechanical properties. Figure 18 also verifies the above points. The analysis showed that the optimal content of xylene was $25 \mathrm{~g}$, and at this content value, the gel time of the 
polyurethane elastomer was $30 \mathrm{~min}$, the $2 \mathrm{~h}$ compressive strength was $38.2 \mathrm{MPa}$, the $2 \mathrm{~h}$ tensile strength was 28.5 $\mathrm{MPa}$, the dry bonding strength was 3.7 $\mathrm{MPa}$, and the wet bonding strength was $2.7 \mathrm{MPa}$.

\subsubsection{Proposal on proportioning of polyurethane material for mud pumping of ballastless track}

Analysis of the test results showed that when polyethers $\mathrm{A}$ and B were mixed at a mass ratio of $3: 1$ to produce a $200 \mathrm{~g}$ polyol mixture, with isocyanate content of $90 \mathrm{~g}$, chainextending cross-linking agent (1,4-butanediol) content of $27 \mathrm{~g}$ and solvent (xylene) content of $25 \mathrm{~g}$, the synthesized polyurethane elastomer had the best physical and mechanical properties. Although polymer materials have been used for the treatment of mud pumping in subgrade beds under ballastless tracks, theoretical research progress has been slow and inadequate, with unclear performance parameters of the related materials and a lack of normative documentation. According to the Chinese high-speed railway ballastless track line maintenance rules (trial) [47], polymer materials can be used to repair the expansion joints of track slabs and base plates, support layer cracks, and address mortar delamination in joints and other issues. By synthesizing the requirements for material properties according to this rule in Refs. [37, 38], we proposed a series of material performance parameters, which were compared with the properties of the polyurethane materials synthesized in this work, as shown in Table 4.

\section{Dynamic tests using polyurethane for the treatment of mud pumping of ballastless tracks}

Grouting was performed on-site in the area of intercity railway mud pumping to verify the efficacy of the proposed polyurethane material ratio. The material ratio was designed according to methods described in Sect. 2.3.5, and the material performance is shown in Table 4. Mud pumping in the subgrade bed was treated according to the following procedures: (1) A quick-setting polymer mortar was used to seal the side seams of the base plate and the enclosed roadbed layer, forming a closed grouting space. (2) Then, along the longitudinal direction of the line, the track slab was connected, and holes were drilled at an angle of $45^{\circ}$ along the seam of the base plate to the depth of the surface of the bed. The hole diameter was $10 \mathrm{~mm}$ and the hole spacing was $60 \mathrm{~cm}$. The holes were drilled $5 \mathrm{~cm}$ deep into the surface of the bed to ensure the filling degree of the grouting, as shown in Figs. 19 and 20. (3) The grouting pipe was installed and connected with a high-pressure air pump. High-pressure air flushing was performed to the bottom of the base plate to wash away the accumulated water and mud between the base plate and the surface layer of the bed. (4) Finally, the grouting machine was connected to the grouting pipe, and the configured polyurethane grouting was poured into the hopper of the grouting machine. The grouting pressure was adjusted to about $0.2 \mathrm{MPa}$, and grouting operations commenced. Figure 21 illustrates the on-site grouting operations, where the grouting pressure did not exceed 0.4 MPa. Before and after grouting, a dynamic driving test was conducted on the test section to compare and analyze the dynamic responses of the track structure before and after the renovation, and to

Table 4 Performance comparison of the polyurethane material

\begin{tabular}{|c|c|c|c|}
\hline Parameter & Unit & Measured value & Limit value $[37,38,44]$ \\
\hline Viscosity & $\mathrm{mPa} \cdot \mathrm{s}$ & 287 & $\leq 300$ \\
\hline Gel time & $\min$ & 30 & $\leq 30$ \\
\hline \multicolumn{4}{|l|}{ Tensile strength } \\
\hline $2 \mathrm{~h}$ & $\mathrm{MPa}$ & 7.5 & $\geq 6$ \\
\hline $7 \mathrm{~d}$ & $\mathrm{MPa}$ & 22.9 & $\geq 20$ \\
\hline \multicolumn{4}{|l|}{ Compressive strength } \\
\hline $2 \mathrm{~h}$ & $\mathrm{MPa}$ & 10.3 & $\geq 6$ \\
\hline $7 \mathrm{~d}$ & $\mathrm{MPa}$ & 36.3 & $\geq 30$ \\
\hline \multicolumn{4}{|l|}{ Bonding strength } \\
\hline Dry bonding & $\mathrm{MPa}$ & 3.6 & $\geq 3.0$ \\
\hline Wet bonding & MPa & 2.7 & $\geq 2.0$ \\
\hline Compression failure deformation rate & $\%$ & 60.5 & - \\
\hline Tensile elongation at break & $\%$ & 94.3 & - \\
\hline
\end{tabular}




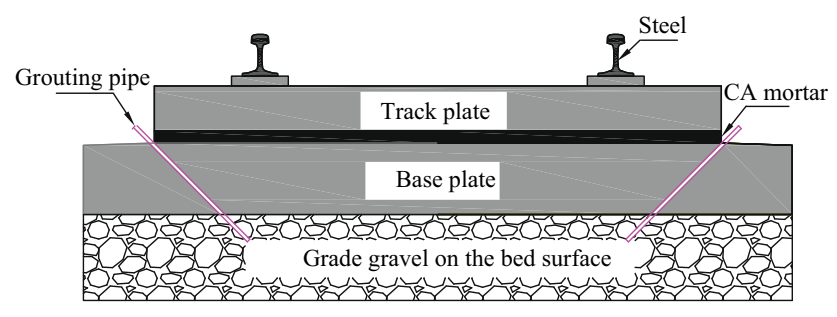

Fig. 19 Sketch of the grouting treatment section

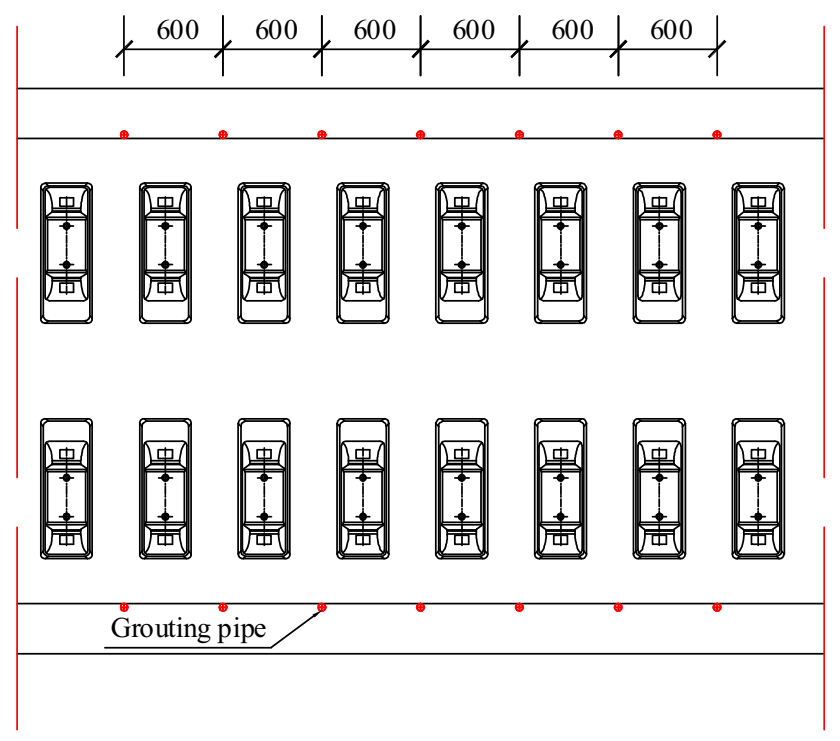

Fig. 20 Layout of the grouting points

examine the treatment effects of the designed polyurethane material.

\subsection{Test program}

Representative cross sections were selected from the mudflushing section of an intercity railway, with sensors installed for testing, and the line was a CRTSI slab ballastless track. CA-YD-117 piezoelectric accelerometers and dynamic piezoelectric displacement meters were placed on the outer edge of the top surface of the track plate, the outer edge of the top surface of the base plate, and the top surface of the enclosed roadbed layer (near the base plate), as shown in Fig. 22. A DH5922 dynamic acquisition instrument was used for data acquisition. During the test period, a CRH2C electric multiple unit (EMU) was run on the line, where the marshaling form was 8M8T, with a total of 16 sections. The total length of the train was $401.4 \mathrm{~m}$, with a bogie center distance of $17.5 \mathrm{~m}$, wheelbase of $2.5 \mathrm{~m}$, and an average axle load of $14 \mathrm{t}$. During the test, the train speed was about $250 \mathrm{~km} / \mathrm{h}$.
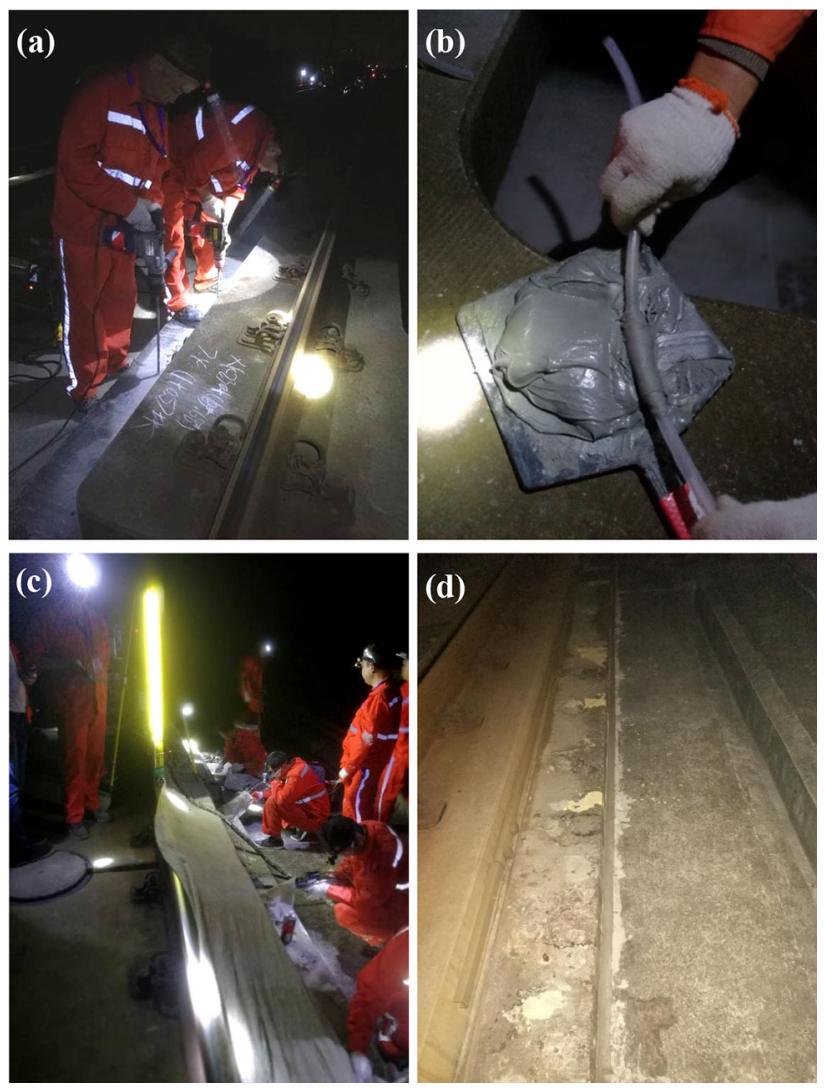

Fig. 21 Layout of the grouting points: a hole layout and drilling; b grouting pipe placement; $\mathbf{c}$ grouting; $\mathbf{d}$ track after grouting

\subsection{Test result analysis}

\subsubsection{Acceleration}

Acceleration is the main indicator for analyzing structural vibration responses, and its value affects the comfort and safety of train operations. Figure 23 shows the vibration acceleration-time history curve of each structural layer of the ballastless track subgrade at different train speeds, before and after the foundation bed was strengthened by grouting.

Figure 23 shows evident peaks in the acceleration-time history curves of each structural layer, and each peak corresponded to the acceleration response of the structural layer when a single bogie of the EMU passed by. Between the adjacent peaks, the acceleration value response rapidly decayed; however, the attenuation interval was very short. There were also more noticeable loading and unloading processes when the train passed the test point. Before grouting, the acceleration amplitude ranges of the top surfaces of the track slab, base slab, and enclosed roadbed layer were $4.59-5.36 \mathrm{~m} / \mathrm{s}^{2}, \quad 1.85-2.21 \mathrm{~m} / \mathrm{s}^{2}$, and $0.92-1.17 \mathrm{~m} / \mathrm{s}^{2}$, respectively. After grouting, the amplitude ranges for each structural layer were significantly reduced, 


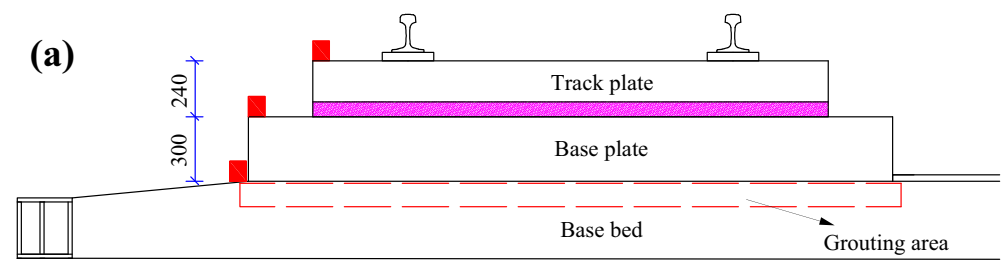

Vibration acceleration sensor and vibration displacement sensor

(unit: $\mathrm{mm}$ ) (b)

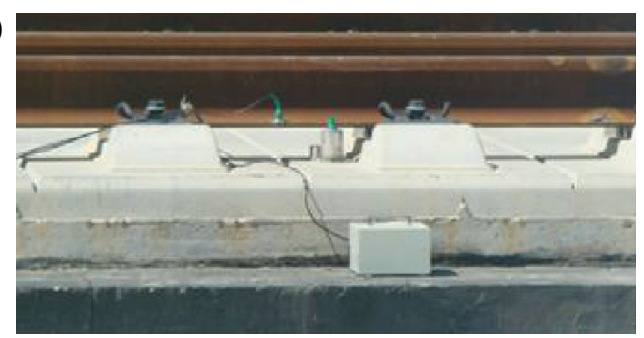

Fig. 22 Layout of the dynamic test sensors: a schematic of sensor arrangement; b sensors installed on site

and the acceleration amplitude ranges of the top surfaces of the track slab, base slab, and shoulder were $2.85-3.59 \mathrm{~m} /$ $\mathrm{s}^{2}, 0.81-1.12 \mathrm{~m} / \mathrm{s}^{2}$, and $0.56-0.81 \mathrm{~m} / \mathrm{s}^{2}$, respectively.

The acceleration values for each structural layer before and after grouting were calculated, and the average distributions of vibration acceleration amplitudes for each structural layer before and after grouting are shown in Fig. 24. Figure 24 shows that the average vibration acceleration amplitude value for each structural layer was significantly reduced after polyurethane grouting treatment. The average vibration acceleration amplitudes at the top surfaces of the track slab, base slab, and shoulder were reduced from 4.59 (before grouting) to $3.27 \mathrm{~m} / \mathrm{s}^{2}$ (after grouting), from 1.97 (before grouting) to $0.95 \mathrm{~m} / \mathrm{s}^{2}$ (after grouting), and from 1.04 (before grouting) to $0.69 \mathrm{~m} / \mathrm{s}^{2}$ (after grouting), which corresponded to decreases of $28.8 \%, 52 \%$, and $33.6 \%$, respectively. Therefore, after grouting reinforcement of the ballastless track was complete, the void area was filled and the contact state was more uniform, which significantly changed the connection between the bottom of the base plate and the contact layer of the surface layer of the subgrade bed, enhanced the transmission performance of the vibration waves between the layers, and restored the supporting effect of the subgrade to the ballastless track structure and the effect of vibration energy consumption.

\subsubsection{Dynamic displacement}

Vibration displacement is a vital indicator for evaluating the dynamic response performance of ballastless track structures, and it reflects the degree of dynamic effects of traffic load on the structure under the track. Excessive dynamic displacement can seriously affect the smoothness and stability of the train, and even the safety of train operations. Figure 25 shows the dynamic displacementtime history curve of the top surface of the base plate of the test section before remediation. The $\mathrm{W}$-shaped waveform in the figure shows the loading and unloading processes of the top surface of the base plate at the test position as the bogie wheels passed by. As shown in the figure, when the train passed the test section, the dynamic displacement curve drifted. After the seam was cut on the spot, observations under the base plate showed a clear seam between the surface of the bed and the base plate. The base plate had poor contact with the surface of the base bed, and the power transmission was not smooth. The dynamic displacement of the base plate as a rigid material and the surface of the flexible base bed was inconsistent, which caused large vibration displacement fluctuations of the upper track structure. This phenomenon posed a significant hidden danger to driving safety.

The average value of the dynamic displacement amplitude for each structural layer of the ballastless track before and after grouting was calculated according to the test data, and the vibration displacement distribution of each structural layer in the ballastless track is drawn in Fig. 26. The figure shows that designing polyurethane for treating the mud-flushing section of the foundation bed could effectively improve the dynamic response distribution of the track structure. Before the renovation, the average dynamic displacement amplitude values at the top surfaces of the track slab, base slab, and enclosed subgrade layer were $0.61 \mathrm{~mm}, 0.28 \mathrm{~mm}$, and $0.06 \mathrm{~mm}$, respectively. The dynamic displacements of the structural layers showed large differences, where the dynamic displacement of the top surface of the enclosed subgrade layer was almost zero, which showed that the contact between the track structure and the surface of the subgrade was very poor. The vertical dynamic transmission path was interrupted between the base plate and the surface layer of the subgrade bed. When the actual train passed over the test section, the car body shook noticeably and the safety of train operations was at risk. After grouting with the designed polyurethane material, the average dynamic displacement amplitude values at the top surfaces of the track slab and the base plate decreased to $0.36 \mathrm{~mm}$ and $0.18 \mathrm{~mm}$, resulting in decreases of $41 \%$ and $35.7 \%$, respectively. The average dynamic displacement amplitude value at the top surface of the enclosed layer of the roadbed increased to $0.15 \mathrm{~mm}$, reflecting an increase of $150 \%$. Moreover, the average difference in the dynamic displacement amplitude of each 

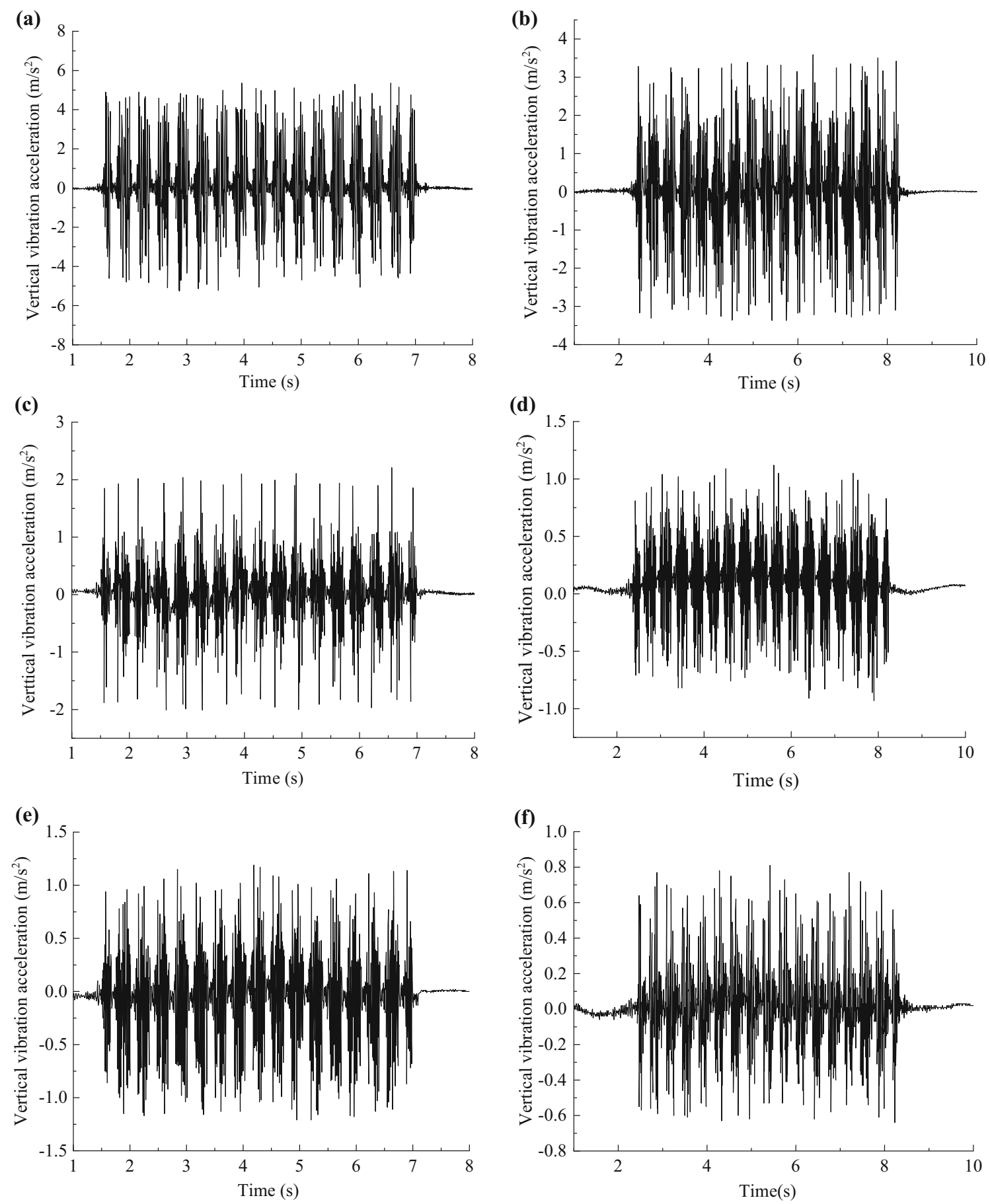

Fig. 23 Dynamic responses in the flushing section: a track surface before grouting; $\mathbf{b}$ track surface after grouting; $\mathbf{c}$ base plate surface before grouting; $\mathbf{d}$ base plate surface after grouting; e shoulder surface before grouting; $\mathbf{f}$ shoulder surface after grouting

structural layer after grouting treatment decreased, that is, the dynamic displacement of each structural layer was more coordinated. The average amplitude distribution of the dynamic displacement of each structural layer after grouting was relatively close to the dynamic measurement data of the ballastless track with intact subgrade beds in the literature [3]. The test data showed that the polyurethane with the appropriate design ratio exhibited good fluidity and could fill the gaps between the fillers on the surface of the bed, filling the seam between the surface of the bed and the contact interface of the base plate. It could also restore the integrity of the bed surface and improve the gap between the bed surface and the base plate. The contact characteristics between the plates promoted the formation 


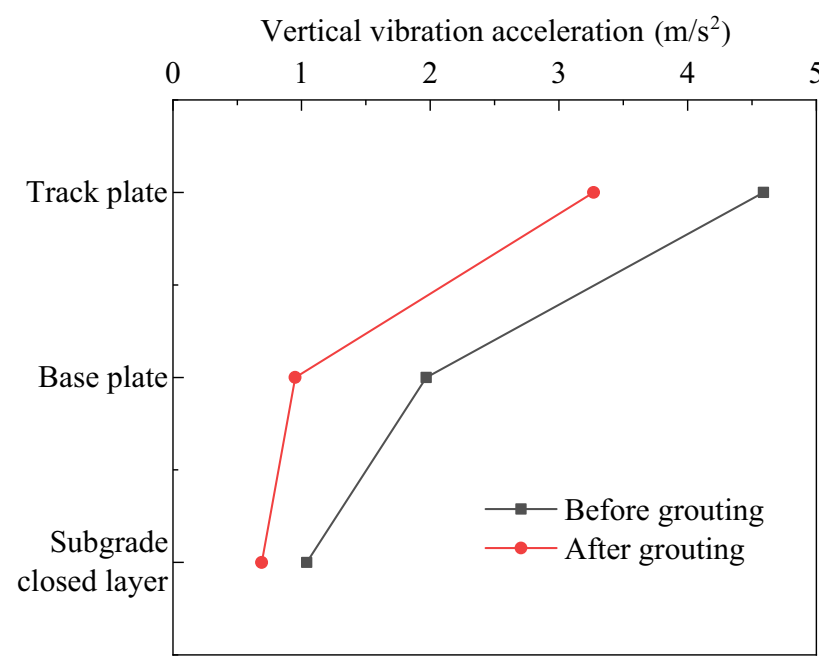

Fig. 24 Distribution of the mean acceleration amplitude values before and after grouting in each structural layer of the ballastless track

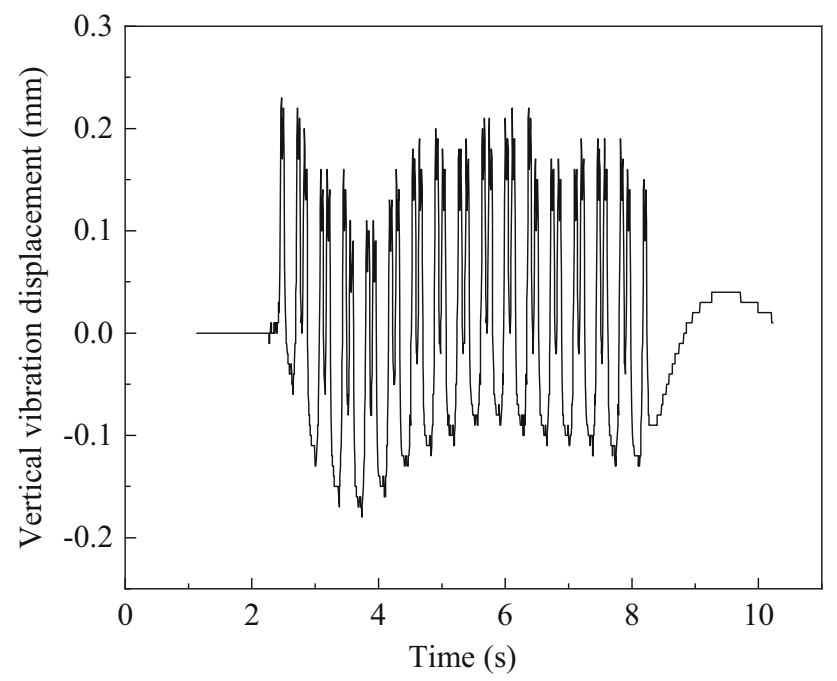

Fig. 25 Base plate dynamic displacement-time history curve

of a good dynamic response coordination mechanism between the ballastless track and the surface of the subgrade bed, and the designed polyurethane material exhibited a good remediation effect.

\section{Conclusions}

Polyurethane materials can be used to treat mud pumping in subgrade beds under ballastless tracks. To propose the proportioning of polyurethane materials, indoor material tests were first carried out, and then on-site dynamic tests were performed to verify the grouting effect of the proposed polyurethane. The main conclusions were as follows:

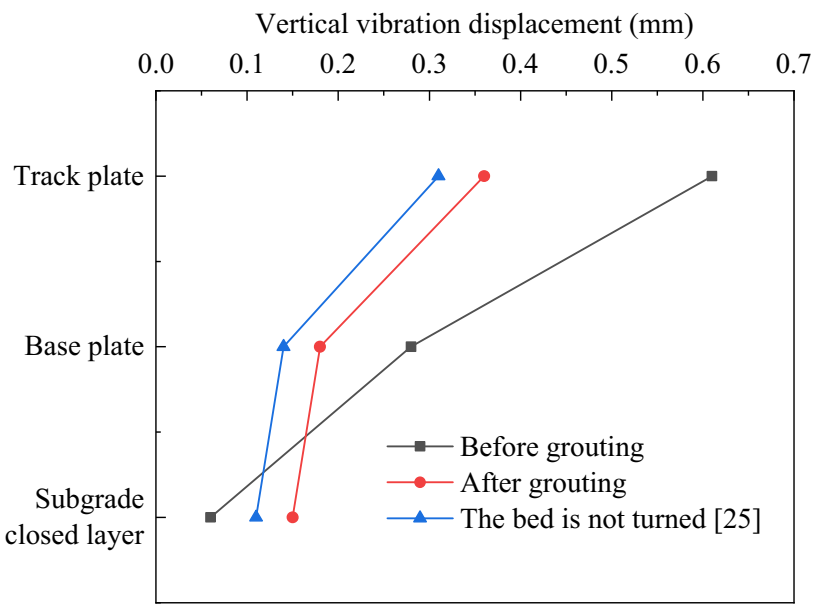

Fig. 26 Comparison of dynamic displacement amplitude values of each layer of the ballastless track before and after grouting

(1) The mixing ratios of different polyols significantly influenced the strength and deformation of the polyurethane elastomer. As the amount of polyether polyol A increased, the mechanical properties of the polyurethane elastomer gradually improved. However, with an excessive amount of polyether, the rigid polymer particles in the elastomer increased, flexibility decreased, the probability of brittle failure increased, and the mechanical properties of the elastomer became weaker.

(2) The relationship curve between isocyanate (PM200) content, strength, and deformation exhibited threestage characteristics. As the content increased, the strength of the polyurethane elastomer increased, and the deformation rate decreased. The adhesive strength of the polyurethane elastomer also increased and then decreased with increasing isocyanate (PM200) content.

(3) With increasing 1,4-butanediol content, the gel time of the polyurethane slurry decreased linearly, and the decrease was relatively large. The $2 \mathrm{~h}$ compressive and $2 \mathrm{~h}$ tensile strengths of the polyurethane elastomer increased at a uniform rate. Also, the strength and deformation of the polyurethane elastomer and 1,4butanediol content increased and then decreased. When 1,4-butanediol content was within a certain range, the content increase promoted the cross-linking reaction rate, which shortened the curing time of the polyurethane slurry and allowed it to strengthen faster.

(4) As a solvent, xylene increased the gelation reaction rate of the polyurethane slurry, allowing it to cure and form in a relatively short amount of time. However, with excessive amount, xylene was solvated in excess, which increased intermolecular fluidity. Thus, in terms of setting time, there was an optimal amount of xylene dosage. 
(5) Through a single-factor control variable experiment, the optimal mass ratio among polyether A, polyether B, PM200, 1,4-butanediol, and xylene was 150:50:90:27:25. The gelation time of the polyurethane elastomer prepared according to this ratio was $30 \mathrm{~min}$, where the compressive strength after $2 \mathrm{~h}$ was 10.3 MPa, the tensile strength after $2 \mathrm{~h}$ was $7.5 \mathrm{MPa}$, the dry bonding strength was $3.6 \mathrm{MPa}$, the wet bonding strength was $2.7 \mathrm{MPa}$, and the elongation at break was $94.3 \%$.

(6) The dynamic field test showed that the contact characteristics between the surface layer of the subgrade bed and the base plate improved after grouting treatment of the subgrade bed under the ballastless track with the designed proportion of polyurethane grouting. As a result, the coordination of the dynamic response between the track structure and the subgrade bed was restored, ensuring the safety and comfort of line operations, and with a good application effect.

In this study, although the proportion of polyurethane materials suitable for the treatment of mud pumping in the subgrade bed under ballastless tracks was proposed, and it exhibited a good field application effect, the dynamic performance and durability of the material are still unknown. Therefore, in a follow-up study, more comprehensive research will be needed to provide a basis for the application of polyurethane materials in the treatment of mud pumping.

Acknowledgements The authors gratefully acknowledge the financial support for this research by the National Natural Science Foundation of China (Grant Nos. 51978588 and 52078434). We thank LetPub (www.letpub.com) for its linguistic assistance during the preparation of this manuscript.

Open Access This article is licensed under a Creative Commons Attribution 4.0 International License, which permits use, sharing, adaptation, distribution and reproduction in any medium or format, as long as you give appropriate credit to the original author(s) and the source, provide a link to the Creative Commons licence, and indicate if changes were made. The images or other third party material in this article are included in the article's Creative Commons licence, unless indicated otherwise in a credit line to the material. If material is not included in the article's Creative Commons licence and your intended use is not permitted by statutory regulation or exceeds the permitted use, you will need to obtain permission directly from the copyright holder. To view a copy of this licence, visit http://creativecommons. org/licenses/by/4.0/.

\section{References}

1. Phong PD (2015) Study on the mud pumping mechanism and reinforcement effect for graded gravel in high-speed railway ballastless track surface layer of subgrade bed. Dissertation, Southwest Jiaotong University, Chengdu (in Chinese)

2. Liu MS, Luo Q, Guo JH et al (2019) Mechanism of frost boiling and optimization of drainage design in ballastless track subgrade bed. J Beijing Jiaotong Univ 43(3):16-25 (in Chinese)

3. Zhang WC, Su Q, Liu T et al (2014) Research on vibration characteristics of ballastless track subgrade under frost boiling at subgrade bed. Rock Soil Mech 35(12):3556-3562 (in Chinese)

4. Yang F, Wang T, Yang JF et al (2016) Research on Influence of mud-pumping and renovation of slab ballastless track subgrade on track irregularity. Railw Eng 11:129-132 (in Chinese)

5. Karol RH (2007) Chemical grouting and soil stabilization, revised and expanded, 3rd edn. CRC Press, Boca Raton

6. Li LP, Li SC, Zhang QS et al (2010) Experimental study of a new polymer grouting material. Chin J Rock Mech Eng 29:3150-3156

7. Qian X, Xiao F (2020) Applications of epoxy materials in pavement engineering. Constr Build Mater 235:117529

8. Jiang H, Zhong R, Peng Z (2019) Study on preparation of chemical grouting and its hydraulic properties and application for water seepage safety. J Coast Res 94(sp1):291-295

9. Kazemian S, Huat BBK, Arun P et al (2010) A review of stabilization of soft soils by injection of chemical grouting. Aust $\mathbf{J}$ Basic Appl Sci 4(12):5862-5868

10. Yang Z, Cheng X (2013) A performance study of high-strength microbial mortar produced by low pressure grouting for the reinforcement of deteriorated masonry structures. Constr Build Mater 41:505-515

11. Fangtian W, Cun Z, Shuaifeng W et al (2016) Whole section anchor-grouting reinforcement technology and its application in underground roadways with loose and fractured surrounding rock. Tunn Undergr Space Technol 51:133-143

12. Zhang DL, Sun F, Li PF (2012) Mechanism of composite grouting in subsea tunnel and its application. Chin J Rock Mech Eng 31(3):445-452 (in Chinese)

13. Mishra D, Boler H, Tutumluer E et al (2016) Effectiveness of chemical grouting and stone blowing as remedial measures to mitigate differential movement at railroad track transitions. In: ASME/IEEE joint rail conference, vol. 49675. Columbia, April 12-15, 2016

14. Einsalo K (2019) Post-grouting in aggressive environment: case ring rail line. In: ISRM 9th Nordic grouting symposium. Helsinki

15. Huang JJ, Su Q, Cheng YM et al (2019) Improved performance of the subgrade bed under the slab track of high-speed railway using polyurethane adhesive. Constr Build Mater 208:710-722

16. Akindoyo JO, Beg MDH, Ghazali S et al (2016) Polyurethane types, synthesis and applications-a review. RSC Adv 6:114453-114482

17. Krol P (2007) Synthesis methods, chemical structures and phase structures of linear polyurethanes. Properties and applications of linear polyurethanes in polyurethane elastomers, copolymers and ionomers. Prog Mater Sci 52(6):915-1015

18. Nguyen TT, Indraratna B, Kelly R, Phan NM, Haryono F (2019) Mud pumping under railtracks: mechanisms, assessments and solutions. Aust Geomech J 54:59-80

19. Gundavaram D, Hussaini SKK (2019) Polyurethane-based stabilization of railroad ballast - a critical review. Int J Rail Transp 7(3):219-240

20. Li H, Yi S, Zheng X et al (2013) Performance and application of ballast adhesive for high-speed railway. Polyurethane Ind 28(1):26-28

21. Hussain N, Bonnia NN, Hirzin R et al (2019) Effect of NCO/OH ratio on physical and mechanical properties of castor-based polyurethane grouting materials. J Phys Conf Ser 1349:012113

22. Yang Z, Zhang X, Liu X et al (2017) Flexible and stretchable polyurethane/waterglass grouting material. Constr Build Mater 138:240-246 
23. Yang S, Xu X, Zhou X et al (2011) Preparation of polyurethane grouting and reinforcement materials. Appl Chem Ind 40(2):295-298, 302 (in Chinese)

24. Zheng XG (2017) Expansion characteristics of polymer grouting material cured under pressure and mechanical properties of its consolidated body. China Railw Sci 38(1):9-15 (in Chinese)

25. Gao X, Wei Y, Wang F et al (2017) Fatigue resistant and microstructure evolution of polyurethane grout materials under uniaxial compression. Acta Mater Compos Sin 34(3):550-556 (in Chinese)

26. Wei Y, Wang F, Gao X et al (2017) Microstructure and fatigue performance of polyurethane grout materials under compression. J Mater Civ Eng 29(9):04017101

27. Liu K, Li Y, Wang F et al (2019) Analytical and model studies on behavior of rigid polyurethane composite aggregate under compression. J Mater Civ Eng 31(3):04019007

28. Liu K, Liang W, Ren F et al (2019) The study on compressive mechanical properties of rigid polyurethane grout materials with different densities. Constr Build Mater 206:270-278

29. Xiang J, Liu L, Cui X et al (2019) Effect of fuller-fine sand on rheological, drying shrinkage, and microstructural properties of metakaolin-based geopolymer grouting materials. Cement Concr Compos 104:103381

30. Khotbehsara MM, Manalo A, Aravinthan T et al (2019) Effect of elevated in-service temperature on the mechanical properties and microstructure of particulate-filled epoxy polymers. Polym Degrad Stab 170:108994

31. Wang J, Li X, Fang H et al (2020) Statistical characteristics of polymer grouting material microstructure. Adv Civ Eng. https:// doi.org/10.1155/2020/8847494

32. Saleh S, Yunus NZM, Ahmad K et al (2020) Micro-level analysis of marine clay stabilised with polyurethane. KSCE J Civ Eng 24(3):807-815

33. Anagnostopoulos CA (2005) Laboratory study of an injected granular soil with polymer grouts. Tunn Undergr Space Technol 20(6):525-533

34. Fang H, Li B, Wang F et al (2018) The mechanical behaviour of drainage pipeline under traffic load before and after polymer grouting trenchless repairing. Tunn Undergr Space Technol 74:185-194

35. Hao M, Wang F, Li X et al (2018) Numerical and experimental studies of diffusion law of grouting with expansible polymer. J Mater Civ Eng 30(2):04017290
36. Guo C, Sun B, Hu D et al (2019) A field experimental study on the diffusion behavior of expanding polymer grouting material in soil. Soil Mech Found Eng 56(3):171-177

37. Wang D, Sui W (2012) Grout diffusion characteristics during chemical grouting in a deep water-bearing sand layer. Int $\mathrm{J}$ Min Sci Technol 22(4):589-593

38. Festel G (2004) Synthesis and properties of segmented polyurethane elastomers with molecularly uniform hard segments based on 1,5-naphthalene diisocyanate and 1,4-butanediol. Chin Polym Bullet 6:42-62

39. Fu HJ, Yu CK, Luo JX et al (2012) Effect of chain extender and crosslinking agent on the properties of polyurethane elastomer based on NDI. China Plastics 10:31-35 (in Chinese)

40. Li D (2019) Development and application of polyurethane for repairing mud pumping of subgrade of ballastless track. Dissertation, Southwest Jiaotong University, Chengdu (in Chinese)

41. Liu CJ (2016) Research on new materials and construction technology of railway subgrade mud pumping. Dissertation, Southwest Jiaotong University, Chengdu (in Chinese)

42. National Development and Reform Commission (2008) JC/T 1041-2007: epoxy grouting resin for concrete crack. Chinese Building Materials Press, Beijing (in Chinese)

43. State Administration for Market Regulation, Standardization Administration (2009) JB/T 2567-2008: Test methods for properties of resin casting body. Standards Press of China, Beijing (in Chinese)

44. State Administration for Market Regulation, Standardization Administration (2009) GB/T 7193-2008: Test methods for unsaturated polyester resins. Standards Press of China, Beijing (in Chinese)

45. Zhong CM, Zhu H, Yu C et al (2014) Preparation and characterization of high performance polymer polyols. Polym Bull 12:149-156

46. Tatai L, Moore TG, Adhikari R et al (2007) Thermoplastic biodegradable polyurethanes: the effect of chain extender structure on properties and in-vitro degradation. Biomaterials 28(36):5407-5417

47. China State Railway Group Co., Ltd (2012) Chinese high-speed railway ballastless track line maintenance rules (trial). China Railway Publishing House Co., Ltd, Beijing (in Chinese) 